76

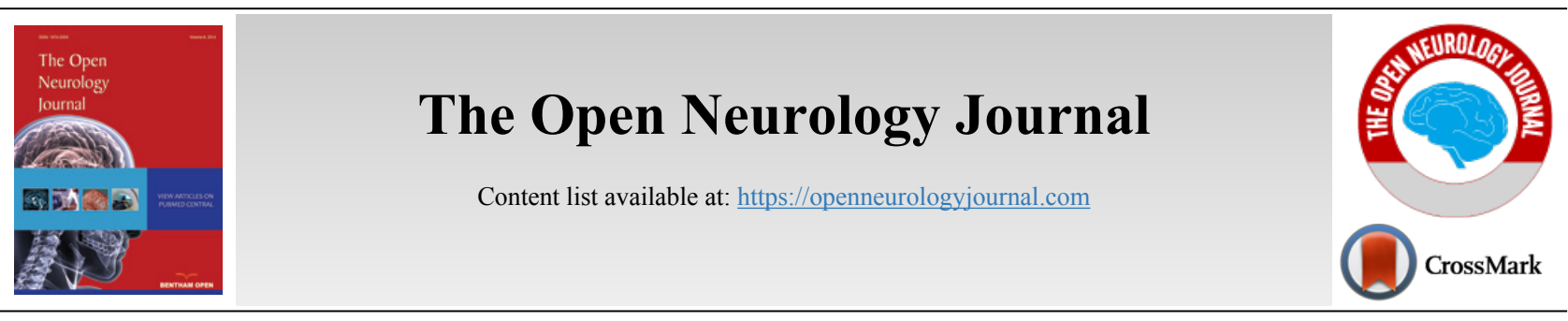

RESEARCH ARTICLE

\title{
Primary Thalamic Haemorrhage - Clinical Profile and Prognostic Predictors from a Series of 117 Cases
}

\author{
Girish Menon, Ajay Hegde, Lakshman I Kongwad and Sandesh Omkarappa \\ ${ }^{1}$ Department of Neurosurgery, Kasturba Medical College, Manipal Academy of Higher Education, Manipal 576104, India
}

\begin{abstract}
:
Background:

Studies on isolated primary thalamic hematomas are limited. This study analyses 117 patients with primary thalamic hematomas and attempts to identify the various prognostic factors influencing the outcome.

Materials and Methods:

A retrospective analysis of the case records was carried out to analyse the following prognostic parameters - GCS on admission, comorbidities like systemic hypertension and diabetes mellitus, side and site of hematoma, volume of the clot, presence of intraventricular haemorrhage (IVH), development of hydrocephalus, and the role of surgical intervention. A Chi-square test was used to compare categorical variables, and Student ttest and Mann Whitney test were applied to calculate the P-value for continuous variables for univariate statistics. Binary Logistic regression was used for multivariate analysis.

\section{Results and Discussion:}

This study group comprised 67 men and 50 women with a mean age of $62.05 \pm 11.71$ years. The mean GCS on admission in the study group was $11.56 \pm 3.28$. The mean clot volume was $13 \pm 9.5 \mathrm{ml}$ and majority $(89.74 \%)$ of the patients had clots with a volume of less than $20 \mathrm{ml}$. An intraventricular extension was noted in 98 patients. Craniotomy and surgical evacuation were performed in only two patients while external ventricular drainage with urokinase instillation was performed in 23 patients. Of the 117 patients, 3 had anterior thalamic clots, 19 had posterior thalamic clots, 13 had medial clots, 53 had lateral thalamic bleeds and 29 had global clots. The overall three-month mortality with thalamic bleeds was $28.2 \%$. At the end of three months, 59 patients $(50.42 \%)$ had a favourable outcome $(\mathrm{mRS}<4)$. On univariate analysis, male sex, dominant side bleed, preoperative GCS of less than $8(\mathrm{p}<0.001)$, presence of hydrocephalus $(\mathrm{p}<0.004)$ and a need for EVD ( $<<0.012)$ were found to be significantly associated with mortality and poor outcome. Similarly, clot volume less than $20 \mathrm{ml}$, right-sided bleed and surgical evacuation were associated with a favourable outcome $(\mathrm{p}<0.001)$. On multiple logistic regression, age, volume of hematoma and GCS on admission were predictors for mortality and volume of hematoma was a significant predictor of poor outcome.

\section{Conclusion:}

Thalamic hematomas include a spectrum of clots of varying dimensions at different locations and the outcomes need not be uniformly poor. Isolated thalamic hemorrhages are generally small in volume preferentially located in the lateral thalamus. Patients with right-sided bleeds and small clot volume perform well. Male sex, poor GCS on admission, clot volume above $20 \mathrm{ml}$, intraventricular extension and a need for external ventricular drainage adversely influence the outcome.
\end{abstract}

Keywords: ICH, Intracerebral haemorrhage, Outcome predictors, Thalamic haemorrhage, Prognostic predictors, Clinical profile.

\section{Article History}

$$
\text { Received: February 12, } 2019
$$

Revised: March 26, 2019

Accepted: May 07, 2019

\section{INTRODUCTION}

Thalamic hematomas represent $8.3-15 \%$ [1] of all SICHs and are known to carry a poor prognosis [2]. Surprisingly stu-

\footnotetext{
* Address correspondence to this author at the Department of Neurosurgery, Room No 12, OPD Block, Kasturba Medical College, Manipal 576104, India; Tel: +91-9900700827;

Emails: Lkongwad@gmail.com, Lakshman.ik@manipal.edu
}

dies on isolated pure thalamic haemorrhages are limited [3 11]. The present study attempts to study the various factors influencing outcome following isolated thalamic haemorrhages in a series of 117 patients. An attempt was also made to analyse the outcome based on the location of the bleed within the thalamus by classifying thalamic bleeds into 5 types according to the major thalamic vascular territories affected. 


\section{MATERIALS AND METHODS}

Case records of all the patients admitted with computerized tomography (CT) evidence of Spontaneous Intracerebral Haemorrhage between $1^{\text {st }}$ January 2015 to $30^{\text {th }}$ December 2017 were retrospectively analysed. Data collected included those pertaining to risk factors, clinical findings, biochemical parameters, radiological findings and details regarding the treatment plan. Informed consent was taken as prescribed by the Ethics Committee, Manipal University as per the Approval No IEC 209/2015. A total of 624 patients were admitted with hypertensive intracerebral haemorrhage in this period. The distribution of clots was predominantly supratentorial (541 patients). Among these patients, 336 had capsuloganglionic hematomas, 117 thalamic and the remaining had lobar hematomas. Patients above the age of 18 with CT evidence of isolated primary thalamic haemorrhage were included in the study. The other exclusion criteria included post traumatic hematomas, intracranial space-occupying lesions with bleed, haemorrhagic transformation of an ischemic stroke, patients with coagulation abnormalities, vascular malformations and aneurysms. All the patients were managed in a neurosurgical intensive care unit with strict monitoring of blood pressure, anti oedema measures and other supportive treatments. External ventricular drainage with instillation of urokinase was performed in patients with GCS less than 13 and having evidence of acute hydrocephalus and intraventricular haemorrhage $(\mathrm{IVH})$. Criteria for surgical evacuation included hematoma volume $>30 \mathrm{ml}$ with midline shift of more than $0.5 \mathrm{~cm}$ measured on non-contrast CT images. Aggressive rehabilitation was initiated as soon as the patient was fit to be shifted out of the intensive care unit. Hematoma volume was calculated by the (abc) $/ 2$ method $[12,13]$ on $5 \mathrm{~mm}$ slices of noncontrast CT on admission. The thalamic hematomas were classified into five types based on the vascular territories of the four major thalamic arteries: anterior type (supplied mainly by the tuberothalamic artery), medial (supplied mainly by the paramedian thalamic-subthalamic artery), lateral (supplied mainly by the thalamogeniculate artery), and posterior (supplied mainly by the posterior choroidal artery and global involving multiple territories (Fig. 1). The outcome determinants were mortality and morbidity as measured using the modified Rankin Scale (mRS) at discharge and 3 months. mRS scores evaluated three months after admission were used to determine clinical outcomes. Patients were divided into 2 groups according to their mRS scores: the favourable outcome group (mRS scores of 1-3), and the poor outcome group (mRS scores of 4-5). The following factors which influence the clinical outcome of patients with thalamic ICHs were analysed - GCS on admission, comorbidities like systemic hypertension and diabetes mellitus, side of $\mathrm{ICH}$, site of hematoma, volume of clot, presence of IVH, development of hydrocephalus, role of surgical intervention like hematoma removal or external ventricular drainage and complications like infection and sepsis. Chi-Square test was used to compare categorical variables and Student t-test and Mann Whitney test were applied to calculate P-value for continuous variables for univariate statistics. Binary Logistic regression was used for multivariate analysis in step forward method. Data analysis was done using IBM SPSS V.24.

\section{RESULTS}

This study retrospectively examined 117 consecutive patients of primary thalamic hematomas comprising 67 men and 50 women. The mean age of the study group was $62.05 \pm$ 11.71 years, in comparison to the mean age of $56.59 \pm 11.93$ years among capsuloganglionic, $57.29 \pm 12.62$ years among lobar and $63.06 \pm 13.54$ years amongst posterior fossa bleeds. Similarly, the sex distribution showed a male preponderance as was seen with our capsuloganglionic bleed cohort. The mean GCS on admission in the study group was $11.56 \pm 3.28$ compared to $10.50 \pm 3.52$ among capsuloganglionic bleeds. A history of hypertension was obtained in 74 patients, and the mean systolic and diastolic blood pressure were $175.81 \pm$ $29.48 \mathrm{mmHg}$ and $100.60 \pm 11.91 \mathrm{mmHg}$ respectively. A history of treatment for diabetes was observed in 40 , and the mean blood sugar on admission was $160.68 \pm 64.33 \mathrm{mg} / \mathrm{dl}$. The mean clot volume was $13 \pm 9.5 \mathrm{ml}$, and IVH was seen in 98 patients. Craniotomy and surgical evacuation were done in only two patients while external ventricular drainage with urokinase instillation was performed in 23 patients (Table 1). Majority of the patients had clots with a volume of less than $20 \mathrm{ml}$ $(89.74 \%)$. None of the patients had a clot volume above $60 \mathrm{ml}$, and only one patient had a clot volume above $40 \mathrm{ml}$. This is in sharp contrast to our capsuloganglionic group where 46 patients had clot volumes above $60 \mathrm{ml}$. We attempted to classify thalamic hematomas based on their anatomic location and vascular supply. Of the 117 patients, 3 had anterior thalamic clots, 19 had posterior thalamic clots, 13 had medial clots and 53 had lateral thalamic bleeds. Twenty-nine patients had bleeds which involved more than one site and were difficult to categorise and were grouped under the group Global (Table 2). IVH and hydrocephalus were predominantly associated with lateral and global haemorrhages $(p<0.05)$ Distribution of clot volume in the different sub locations and their relationship with IVH and hydrocephalus are tabulated in Table 3. The overall 3-month mortality with thalamic bleeds was $28.2 \%$ compared to $31.6 \%$ in our capsuloganglionic cohort. Of the surviving patients, at the end of three months, 58 patients had a favourable outcome (mRS 1-3) and 26 had an unfavourable outcome (mRS 4-5).

The following parameters were analysed for the outcome age, sex, comorbidities, clot volume, preoperative GCS, surgery, clot site, the presence of IVH, hydrocephalus and the need for external ventricular drainage. SICH score was not analysed as a composite as individual parameters were analysed separately. On univariate analysis, male sex, dominant side bleeds $(\mathrm{p}=0.005)$, preoperative GCS of less than $8(p=0.001)$, the presence of hydrocephalus $(p=0.017)$ and a need for EVD $(p=0.004)$ were found to be significantly associated with mortality. Similarly with a clot volume of less than $20 \mathrm{ml}$, and right side bleeds, surgical evacuation was associated with good outcome $(\mathrm{p}<0.001)$. All other factors did not influence the outcome significantly. On multiple logistic regression, age, volume of hematoma and GCS on admission were predictors for mortality while only the volume of hematoma was a significant predictor of poor outcome (Table 4) 
Table 1. Demographics, clinical, radiological and outcome parameters.

\begin{tabular}{|c|c|c|c|c|c|c|}
\hline- & Total $(n=117)$ & Mortality $(n=33)$ & $\mathbf{p}$ & Good Outcome (n=58) & Poor Outcome $(n=26)$ & $\mathbf{P}$ \\
\hline Demographics & - & - & - & - & - & - \\
\hline Age & 62.05 & 66.09 & 0.019 & 60.74 & 59.85 & 0.742 \\
\hline Sex & - & - & 0.011 & - & - & 0.637 \\
\hline Male & 67 & 25 & - & 30 & 12 & - \\
\hline Female & 50 & 8 & - & 28 & 14 & - \\
\hline Hypertension & 74 & 19 & 0.425 & 38 & 17 & 0.991 \\
\hline Previous Stroke & 12 & 2 & 0.348 & 4 & 6 & 0.034 \\
\hline Diabetes & 40 & 10 & 0.55 & 23 & 7 & 0.311 \\
\hline \multicolumn{2}{|c|}{ Clinical Characteristics } & - & - & - & - & - \\
\hline Systolic & 175.81 & 179.39 & 0.413 & 173.45 & 176.54 & 0.668 \\
\hline Diastolic & 100.6 & 101.21 & 0.728 & 100.52 & 100 & 0.859 \\
\hline Volume & 13 & 19.36 & $<0.001$ & 9.15 & 13.53 & \begin{tabular}{|l|}
0.014 \\
\end{tabular} \\
\hline GCS & 11.56 & 9.51 & $<0.001$ & 12.72 & 11.57 & 0.081 \\
\hline Blood Glucose & 160.68 & 172.35 & \begin{tabular}{|l|}
0.239 \\
\end{tabular} & 154.45 & 160.65 & \begin{tabular}{|l|}
0.677 \\
\end{tabular} \\
\hline Side & - & - & \begin{tabular}{|l|}
0.005 \\
\end{tabular} & - & - & 0.034 \\
\hline Right & 56 & 9 & - & 28 & 19 & - \\
\hline Left & 61 & 24 & - & 30 & 7 & - \\
\hline $\mathrm{IVH}$ & 98 & 31 & 0.061 & 46 & 21 & \begin{tabular}{|l|}
0.878 \\
\end{tabular} \\
\hline Hydrocephalus & 54 & 21 & \begin{tabular}{|l|}
0.017 \\
\end{tabular} & 19 & 14 & \begin{tabular}{|l|}
0.067 \\
\end{tabular} \\
\hline Surgery & 2 & 0 & \begin{tabular}{|l|}
0.377 \\
\end{tabular} & 0 & 2 & \begin{tabular}{|l|}
0.033 \\
\end{tabular} \\
\hline EVD & 23 & 12 & 0.004 & 6 & 5 & \begin{tabular}{|l|}
0.264 \\
\end{tabular} \\
\hline Outcome & - & - & - & - & - & - \\
\hline MRS at 3 months & 3.78 & 6 & $<0.001$ & 2.34 & 4.15 & $<0.001$ \\
\hline MRS at Discharge & 4.18 & 5.21 & $<0.001$ & 3.45 & 4.5 & $<0.001$ \\
\hline
\end{tabular}

Table 2. Subgroup analysis of Age, GCS, Volume and clot location.

\begin{tabular}{|c|c|c|c|c|c|c|}
\hline- & $\mathrm{n}=\mathbf{1 1 7}$ & Mortality & $\mathbf{P}$ & Favourable Outcome & Unfavourable Outcome & P Value \\
\hline Age & - & - & - & - & - & - \\
\hline$<40$ & 6 & 0 & 0.176 & $3(50 \%)$ & $3(50 \%)$ & 0.702 \\
\hline $40-60$ & 46 & $11(23.9 \%)$ & - & $25(71.4 \%)$ & $10(28.6 \%)$ & - \\
\hline $60-70$ & 41 & $12(29.3 \%)$ & - & $21(72.4 \%)$ & $8(27.6 \%)$ & - \\
\hline $70>$ & 24 & $10(40 \%)$ & - & $9(64.3 \%)$ & $5(35.7 \%)$ & - \\
\hline Sex & - & - & - & - & - & - \\
\hline Male & 67 & $25(36.8 \%)$ & 0.011 & $30(71.4 \%)$ & $12(28.6 \%)$ & 0.637 \\
\hline Female & 50 & $8(15.7 \%)$ & & $28(66.7 \%)$ & $14(33.3 \%)$ & \\
\hline GCS & - & - & - & - & - & - \\
\hline $\mathrm{GCS}<8$ & 23 & $12(52.2 \%)$ & 0.001 & $6(54.5 \%)$ & $5(45.5 \%)$ & 0.231 \\
\hline 9 to 12 & 36 & $13(35.1 \%)$ & - & $14(60.9 \%)$ & $9(39.1 \%)$ & - \\
\hline $12>$ & 58 & $8(13.6 \%)$ & & $38(76 \%)$ & $12(24 \%)$ & - \\
\hline Mean GCS & - & - & - & - & - & - \\
\hline Clot volume & - & & - & - & - & - \\
\hline$<20 \mathrm{ml}$ & 105 & $24(22.4 \%)$ & $<0.001$ & $58(71.6 \%)$ & $23(28.4 \%)$ & 0.031 \\
\hline $20-40 \mathrm{ml}$ & 11 & $9(81.8 \%)$ & - & 0 & $2(100 \%)$ & - \\
\hline $40-60 \mathrm{ml}$ & 1 & 0 & - & 0 & $1(00 \%)$ & - \\
\hline Clot Location & - & - & - & - & & - \\
\hline Medial & 13 & $4(30.8 \%)$ & 0.564 & $8(88.9 \%)$ & $1(11.1 \%)$ & 0.076 \\
\hline Lateral & 53 & $13(24.5 \%)$ & - & $28(70 \%)$ & $12(30 \%)$ & - \\
\hline Anterior & 3 & 0 & - & 0 & $3(100 \%)$ & - \\
\hline Posterior & 19 & $5(26.3 \%)$ & - & $10(71.4 \%)$ & $4(28.6 \%)$ & - \\
\hline Global & 29 & $11(37.9 \%)$ & - & $12(66.7 \%)$ & $6(33.3 \%)$ & - \\
\hline
\end{tabular}


Table 3. Distribution of clot volume in the different sub locations of thalamic hematomas with IVE and hydrocephalus.

\begin{tabular}{|c|c|c|c|c|c|c|}
\hline \multirow{2}{*}{ Parameter } & \multicolumn{5}{|c|}{ Location } & \multirow{2}{*}{$\mathbf{p}$} \\
\hline & Anterior & Posterior & Medial & Lateral & Global & \\
\hline Volume & - & - & - & - & - & - \\
\hline$<20$ & $3(2.9 \%)$ & $17(16.2 \%)$ & $11(10.5 \%)$ & $50(47.6 \%)$ & $24(22.9 \%)$ & 0.642 \\
\hline $20-40$ & 0 & $2(18.2 \%)$ & $2(18.2 \%)$ & $2(18.2 \%)$ & $5(45.5 \%)$ & - \\
\hline $40-60$ & 0 & 0 & 0 & $1(100 \%)$ & 0 & \\
\hline IVH & $2(2 \%)$ & $17(17.3 \%)$ & $12(12.2 \%)$ & $38(38.8 \%)$ & $29(29.6 \%)$ & 0.011 \\
\hline Hydrocephalus & $2(3.7 \%)$ & $8(14.8 \%)$ & $9(16.7 \%)$ & $17(31.5 \%)$ & $18(33.3 \%)$ & 0.031 \\
\hline
\end{tabular}

Table 4. Logistic regression for factors affecting mortality and poor outcome in our cohort.

\begin{tabular}{|c|c|c|c|}
\hline- & P & OR & 95\% CI \\
\hline Mortality & - & - & - \\
\hline Volume of Hematoma & 0.007 & 1.083 & 1.022 to 1.147 \\
\hline GCS & 0.012 & 0.815 & 0.695 to 0.956 \\
\hline Age & 0.007 & 1.065 & 1.018 to 1.114 \\
\hline Poor Outcome & - & - & - \\
\hline Volume of Hematoma & $<0.001$ & 1.141 & 1.074 to 1.212 \\
\hline
\end{tabular}

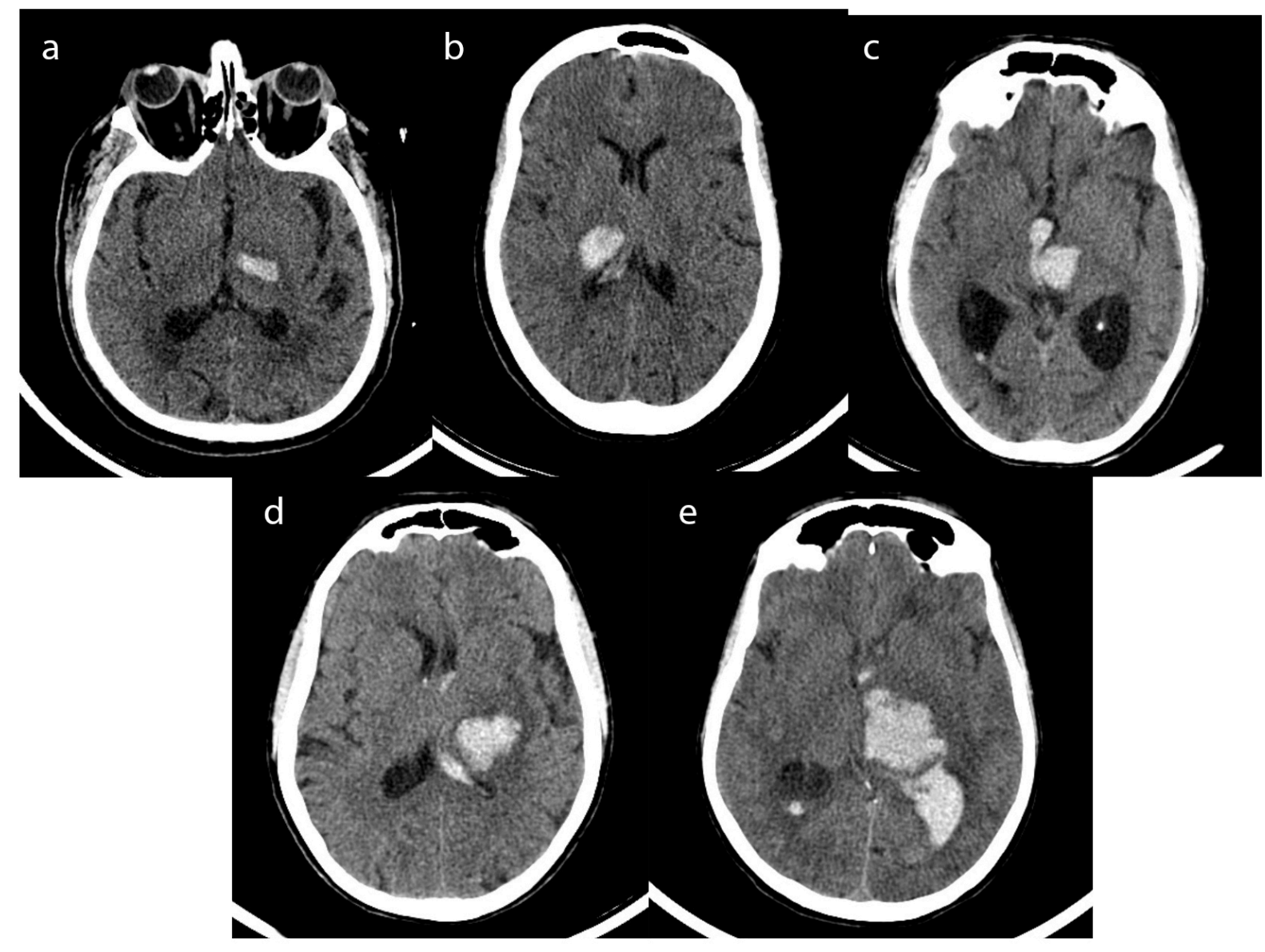

Fig. (1). Representative CT Images of Classification of thalamic haemorrhage a) Anterior b) Posterior c) Medial d) Lateral e) Global 


\section{DISCUSSION}

Clinical series on isolated primary thalamic hematomas are few and thalamic involvement is known to be a negative prognosticator amongst the SICH patients $[14,15]$. Most of the published series have included bleeds extending to adjacent areas like the posterior limb of the internal capsule and basal ganglia. This could explain the poor outcome in these series. Candice et al. made an attempt to study the association between the location and clinical outcome among participants of the INTERACT 2 study, which can be described as one of the largest series of pure thalamic hematomas [16]. Their study cohort included 181 patients with pure thalamic bleeds and 339 patients with thalamic bleeds associated with involvement of the posterior limb of the internal capsule. After multivariate analysis and adjusting for baseline differences, they concluded that thalamic bleeds were associated with death: [OR 1.97 (95\% CI 1.18-3.29)] and poor overall health-related quality of life parameters HRQoL [OR 2.14 (95\% CI $1.32-3.48]$. Associated involvement of the posterior limb of the internal capsule worsens the outcome. The incidence of residual sensory disability with pain syndromes is also known to be higher with thalamic involvement [17]. Nakagawa et al. [17] observed that this poor outcome was irrespective of the size of the clot and relatively small thalamic hematomas can result in poor outcome due to the involvement of the highly dense thalamic nuclei. Our study cohort included patients with exclusive thalamic bleeds and attempts to identify subgroups which carried favourable prognosis in order to optimise aggressive management.

Recently a few studies have examined the topographic location of haemorrhages within the thalamus and their association with patient outcomes. The initial topographical division was based on vascular supply to the thalamus and divided the thalamus into four regions-anterior, medial, posterior and lateral [18]. Neiswander et al. added two more subgroups-central and global referring to patients with bleeds extending to multiple areas [15]. The tuberothalamic artery arising from the posterior communicating artery supplies mainly the anterior part of the thalamus. The paramedian thalamic subthalamic artery arising from the P1 portion of the posterior cerebral artery and the top of the BA mainly supplies the medial part of the thalamus. While the thalamogeniculate artery arising from the $\mathrm{P} 2$ portion of the PCA mainly supplies the lateral part of the thalamus. The posterior choroidal artery arising from the P2 portion of the PCA mainly supplies the posterior part of thalamus including the pulvinar nucleus [10]. The thalamogeniculate artery has many fine and complex anastomoses and often undergoes hypertensive arteriolopathy [10]; and is relatively susceptible to bleed. Lateral thalamic bleeds are thus the most common $[8,9,11,15]$. Anterior thalamic bleeds are usually smaller as the tuberothalmic perforators are small and form a low-pressure system [8] as observed. Our study had only three patients with anterior bleeds and the majority of the patients belonged to the lateral group, a finding similar to what has been described by other authors.

Age is believed to have a predictive value in the clinical outcomes of patients with ICHs in general, including thalamic hemorrhage [7, 19 - 23].SICH is a disease of the elderly, and amongst the SICH patients, thalamic bleeds are more common in the higher age groups. One prospective Japanese cohort study of ICH in 2014 revealed an increased incidence of thalamic haemorrhage in older patients [24] suggesting that thalamic haemorrhage may be a feature of an ageing population. Shinchiur also made a similar observation that the incidence of thalamic hematomas substantially increases in patients aged 70 years or older [18, 24]. We too observed that with advancing age, thalamic bleeds are more common than capsuloganglionic SICH. In our study, the mean age of thalamic hematoma patients was 62.05 years which was marginally higher than the capsuloganglionic bleed cohort (56.59 years). Age was not an important predictor of outcome in the study group of Lee et al. [1]. Age, however, was a significant predictor for mortality in our study with nearly $40 \%$ of patients above the age of 70 years succumbing to the bleed. Age remained a significant predictor for mortality in our study, both after univariate and multivariate analysis, but was not significantly predictive of outcome.

Initial GCS score strongly correlates with clinical outcome in patients with ICHs $[25,26]$. Lee et al. observed that GCS on admission demonstrated an independent association with clinical outcomes (OR 1.761, 95\% CI 1.223-2.536, $\mathrm{P}=0.002$ ). GCS on admission correlated significantly with mortality in

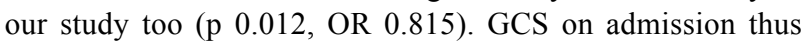
appears to be a uniform predictor for mortality for all types of SICHs including thalamic SICH.

A history of hypertension has been consistently reported as a major risk factor of spontaneous ICHs [27], but its association with clinical prognosis has not been clearly determined [28]. Initial blood pressure is not considered as a risk factor or prognostic factor of ICHs [23], but there are some reports suggesting that intensive reduction of blood pressure may be associated with clinical outcomes of ICHs [29 - 31]. Our observation is similar to that by Lee et al. who reported that neither the history of hypertension [1], diabetes mellitus, use of anticoagulants nor antiplatelet agents are associated with clinical outcomes.

Clot volume is an important prognostic factor in SICH. In the study by Lee et al on a series of thalamic hematomas, clot volume had a significant relationship with the outcome on univariate analysis (OR $0.853,95 \%$ CI $0.783-0.928, \mathrm{P}<0.001$ ) and a borderline association on multivariate analysis(OR 0.920 , $95 \%$ CI $0.839-1.010, \mathrm{P}=0.079$ ). These findings were consistent with those of some previous studies on ICH not restricted to thalamic ICHs [22, 25]. Interestingly, Shah et al. report a contrary finding that clot volume of hematoma influences outcome for putaminal and lobar bleeds but not for thalamic ICH [32]. Clot volume was noted to be a significant prognosticator in our study with a $75 \%$ mortality for patients having clots $20 \mathrm{ml}$. Interestingly, in our study, nearly $89 \%$ of patients had bleeds with clot volume of less than $20 \mathrm{ml}$ which is a serious limitation in interpreting the above finding. The exact reason for this predominance of small volume clots is probably because we have limited our study to pure isolated thalamic bleeds and did not include bleeds extending to the adjacent capsuloganglionic region. 
The influence of the side of thalamic bleed on outcome has not been reported in many studies. In a previous study, the side of hematoma did not relate to clinical outcomes of patients with ICHs [32]. However, haemorrhages affecting the thalamus bilaterally resulted in 5.70 (95\% CI, 1.76e 19.96) increased odds of mortality compared with unilateral bleeds [15]. Rightsided bleeds had lesser mortality and a better chance of favourable outcome in our study suggesting a significant influence of the side of bleed.

The poor prognosis for thalamic hematomas is related to the high incidence of associated IVH [4, 6, 7, 15]. Large thalamic haemorrhages lead to acute hydrocephalus by bleeding into the ventricle and the associated mass effect. Smaller thalamic haemorrhage results in obstructive hydrocephalus caused by bleeding into the third ventricle and poor clinical outcome. IVH can also result in delayed communicating hydrocephalus following resolution of the hematoma. The size of the thalamic hematoma is one of the important factors related to the occurrence of IVH [6]. Kwak et al. suggest that a volume measuring ten $\mathrm{mL}$ or greater has a significant correlation with poor prognosis as well as the risk of IVH [6]. Patients with haemorrhages affecting $75 \% \mathrm{e} 100 \%$ of the thalamus were 5.10 times more likely to die than haemorrhages affecting $0 \%$ to $24.99 \%$ of the thalamus [15]. IVH, surprisingly did not have a significant association with mortality and outcome in our study. Hydrocephalus, on the other hand, was a significant predictor for mortality $(\mathrm{p}<0.017)$.

Controlling the increased ICP with external ventricular drainage EVD is an important therapeutic strategy [23, 33, 34] in the acute stages and practice guidelines for ICHs recommend that EVD for hydrocephalus can be ventricular or via the lumbar route if it is a communicating type of hydrocephalus. In addition, streptokinase is often instilled through an EVD to facilitate the resolution of the IVH. EVD carries a risk of infection which can adversely affect prognosis $[4,6,8,19]$. In Lee's study, on univariate analysis, all the factors related to IVH (presence of IVH, the presence of hydrocephalus, modified Graeb's score of patients with IVH, EVD) were associated with clinical outcomes, but not in multivariate analysis. In Weng's study, minimally invasive THD, in combination with subsequent thrombolysis, was closely associated with a good outcome. Thalamic haemorrhage that requires surgery is associated with poor outcome as was seen with medial thalamic hematomas $[6,8]$. Surgery for hematoma evacuation, however, was not independently associated with clinical outcomes in a few studies $[1,16]$. We too observed that hydrocephalus and a need for EVD significantly influenced mortality and that IVH had a significant negative influence on the outcome.

Several studies have revealed that the site of the bleed has a relationship with the size of the bleed and risk of IVH [15, 18]. In Chung's study as well as Neiswander's study, lateral bleeds had the highest risk for IVH probably due to the collapse of the thalamogeniculate artery which is the largest of the thalamic arteries and penetrates most of the thalamus [8]. In Shinchirus series, medial thalamic bleeds had a high tendency to rupture into the third ventricle causing acute obstructive hydrocephalus and lateral type had a smaller ICH volume with significant association with non-acute hydrocephalus. Their anterior type had the smallest ICH volume and no significant rupture point in the ventricle. In our study lateral thalamic bleeds $(47 \%)$ were the most common followed by global bleeds. We could not establish a definite relation between the site of bleed, risk of IVH and outcomes.

\section{CONCLUSION}

Thalamic hematomas include a spectrum of clots of varying dimensions at varying locations, and the outcomes need not be uniformly poor. Isolated thalamic haemorrhages are generally small in volume preferentially located in the lateral thalamus. Patients with right-sided bleeds and small clot volume do well. Male sex, poor GCS on admission, clot volume above $20 \mathrm{ml}$, intraventricular extension and a need for external ventricular drainage adversely influence the outcome.

\section{ETHICS APPROVAL AND CONSENT TO PARTI- CIPATE}

The study was approved by the Ethics Committee of Manipal University as per the Approval No. IEC 209/2015

\section{HUMAN AND ANIMAL RIGHTS}

No animals/ humans were used for the studies that are the basis of this research.

\section{CONSENT FOR PUBLICATION}

Informed consent was obtained.

\section{AVAILABILITY OF DATA AND MATERIALS}

The data used to support the findings of this study are available from the corresponding author upon request.

\section{FUNDING}

The authors did not receive any funding for this study.

\section{CONFLICT OF INTEREST}

The authors declare no conflict of interest, financial or otherwise.

\section{ACKNOWLEDGEMENTS}

Dr Girish Menon was involved in the design of the study and writeup of the article. Dr Lakshman IK was involved in data collection and edited the manuscript. Dr Sandesh O classified thalamic haemorrhage based on the location. Dr Ajay Hegde was involved in data collection and analysis.

\section{REFERENCES}

[1] Lee S-H, Park K-J, Kang S-H, Jung Y-G, Park J-Y, Park D-H. Prognostic Factors of Clinical Outcomes in Patients with Spontaneous Thalamic Hemorrhage. Med Sci Monit. International Scientific Information. Inc 2015; 21: 2638-46.

[2] Anderson CS, Huang Y, Arima H, et al. Effects of early intensive blood pressure-lowering treatment on the growth of hematoma and perihematomal edema in acute intracerebral hemorrhage: the Intensive Blood Pressure Reduction in Acute Cerebral Haemorrhage Trial (INTERACT). Stroke 2010; 41(2): 307-12.

[http://dx.doi.org/10.1161/STROKEAHA.109.561795] [PMID: 2004 4534]

[3] Steinke W, Sacco RL, Mohr JP, et al. Thalamic stroke. Presentation and prognosis of infarcts and hemorrhages. Arch Neurol 1992; 49(7): 703-10.

[http://dx.doi.org/10.1001/archneur.1992.00530310045011] [PMID: 1497496]

[4] Walshe TM, Davis KR, Fisher CM. Thalamic hemorrhage: a computed tomographic-clinical correlation. Neurology 1977; 27(3): 217-22. 
[http://dx.doi.org/10.1212/WNL.27.3.217] [PMID: 557756]

[5] Piepgras U, Rieger P. Thalamic bleeding: diagnosis, course and prognosis. Neuroradiology 1981; 22(2): 85-91.

[http://dx.doi.org/10.1007/BF00344779] [PMID: 7301110]

[6] Kwak R, Kadoya S, Suzuki T. Factors affecting the prognosis in thalamic hemorrhage. Stroke 1983; 14(4): 493-500. [http://dx.doi.org/10.1161/01.STR.14.4.493] [PMID: 6606870]

[7] Kumral E, Kocaer T, Ertübey NO, Kumral K. Thalamic hemorrhage. A prospective study of 100 patients. Stroke 1995; 26(6): 964-70. [http://dx.doi.org/10.1161/01.STR.26.6.964] [PMID: 7762047]

[8] Chung C-S, Caplan LR, Han W, Pessin MS, Lee K-H, Kim J-M. Thalamic haemorrhage. Brain 1996; 119(Pt 6): 1873-86. [http://dx.doi.org/10.1093/brain/119.6.1873] [PMID: 9009994]

[9] Sáez de Ocariz MM, Nader JA, Santos JA, Bautista M. Thalamic vascular lesions. Risk factors and clinical course for infarcts and hemorrhages. Stroke 1996; 27(9): 1530-6.

[http://dx.doi.org/10.1161/01.STR.27.9.1530] [PMID: 8784125]

[10] Schmahmann JD. Vascular Syndromes of the Thalamus. In: Stroke. Lippincott Williams \& Wilkins 2003.

[http://dx.doi.org/10.1161/01.STR.0000087786.38997.9E]

[11] Kawahara N, Sato K, Muraki M, Tanaka K, Kaneko M, Uemura K. CT classification of small thalamic hemorrhages and their clinical implications. Neurology 1986; 36(2): 165-72.

[http://dx.doi.org/10.1212/WNL.36.2.165] [PMID: 3945386]

[12] Huttner HB, Steiner T, Hartmann M, et al. Comparison of ABC/2 estimation technique to computer-assisted planimetric analysis in warfarin-related intracerebral parenchymal hemorrhage. Stroke 2006; 37(2): 404-8.

[http://dx.doi.org/10.1161/01.STR.0000198806.67472.5c] [PMID: 1637 3654]

[13] Kothari RU, Brott T, Broderick JP, et al. The ABCs of measuring intracerebral hemorrhage volumes. Stroke 1996; 27(8): 1304-5. [http://dx.doi.org/10.1161/01.STR.27.8.1304] [PMID: 8711791]

[14] Arboix A, Comes E, García-Eroles L, et al. Site of bleeding and early outcome in primary intracerebral hemorrhage. Acta Neurol Scand 2002; 105(4): 282-8.

[http://dx.doi.org/10.1034/j.1600-0404.2002.10170.x] [PMID: 1193 9940]

[15] Neisewander BL, Hu K, Tan Z, et al. Location of Thalamic Hemorrhage Impacts Prognosis. World Neurosurg 2018; 116: e525-33. [http://dx.doi.org/10.1016/j.wneu.2018.05.026] [PMID: 29772365]

[16] Delcourt C, Sato S, Zhang S, et al. INTERACT2 Investigators. Intracerebral hemorrhage location and outcome among INTERACT2 participants. Neurology Wolters Kluwer Health, Inc on behalf of the American Academy of Neurology; 2017; 88(15): 1408-

[17] Nasreddine ZS, Saver JL. Pain after thalamic stroke: right diencephalic predominance and clinical features in 180 patients. Neurology 1997; 48(5): 1196-9

[http://dx.doi.org/10.1212/WNL.48.5.1196] [PMID: 9153442]

[18] Teramoto S, Yamamoto T, Nakao Y, Watanabe M. Novel Anatomic Classification of Spontaneous Thalamic Hemorrhage Classified by Vascular Territory of Thalamus. World Neurosurg 2017; 104: 452-8. [http://dx.doi.org/10.1016/j.wneu.2017.05.059] [PMID: 28532917]

[19] Mori S, Sadoshima S, Ibayashi S, Fujishima M, Iino K. Impact of thalamic hematoma on six-month mortality and motor and cognitive functional outcome. Stroke 1995; 26(4): 620-6. [http://dx.doi.org/10.1161/01.STR.26.4.620] [PMID: 7709409]

[20] Hemphill JC, Bonovich DC, Besmertis L, Manley GT, Johnston SC. The ICH Score. Stroke. American Heart Association. Inc 2001; 32(4): 891-7.

[21] $\mathrm{Hu}$ Y-Z, Wang J-W, Luo B-Y. Epidemiological and clinical characteristics of 266 cases of intracerebral hemorrhage in Hangzhou, China. J Zhejiang Univ Sci B SP Zhejiang University Press 2013; 14(6): 496-504

[22] Samarasekera N, Fonville A, Lerpiniere C, et al. Influence of intracerebral hemorrhage location on incidence, characteristics, and outcome: population-based study. Stroke 2015; 46(2): 361-8. [http://dx.doi.org/10.1161/STROKEAHA.114.007953] [PMID: 2558 6833]

[23] Chan E, Anderson CS, Wang X, et al. Significance of intraventricular hemorrhage in acute intracerebral hemorrhage: intensive blood pressure reduction in acute cerebral hemorrhage trial results. Stroke 2015; 46(3): 653-8.

[http://dx.doi.org/10.1161/STROKEAHA.114.008470] [PMID: 2567 7598]

[24] Gotoh S, Hata J, Ninomiya T, et al. Trends in the incidence and survival of intracerebral hemorrhage by its location in a Japanese community. Circ J 2014; 78(2): 403-9.

[http://dx.doi.org/10.1253/circj.CJ-13-0811] [PMID: 24270733]

[25] Cho D-Y, Chen C-C, Lee H-C, Lee W-Y, Lin H-L. Glasgow Coma Scale and hematoma volume as criteria for treatment of putaminal and thalamic intracerebral hemorrhage. Surg Neurol 2008; 70(6): 628-33. [http://dx.doi.org/10.1016/j.surneu.2007.08.006] [PMID: 18207500]

[26] Wang C-W, Liu Y-J, Lee Y-H, et al. Hematoma shape, hematoma size, Glasgow coma scale score and ICH score: which predicts the 30day mortality better for intracerebral hematoma?PLoS ONE. Public Library of Science 2014; 9: p. (7)e102326.

[27] Broderick J, Connolly S, Feldmann E, et al. American Heart Association; American Stroke Association Stroke Council; High Blood Pressure Research Council; Quality of Care and Outcomes in Research Interdisciplinary Working Group. Guidelines for the management of spontaneous intracerebral hemorrhage in adults: 2007 update: a guideline from the American Heart Association/American Stroke Association Stroke Council, High Blood Pressure Research Council, and the Quality of Care and Outcomes in Research Interdisciplinary Working Group. Stroke 2007; 38(6): 2001-23. [http://dx.doi.org/10.1161/STROKEAHA.107.183689] [PMID: 1747 8736]

[28] Thrift AG, McNeil JJ, Forbes A, Donnan GA. Melbourne Risk Factor Study (MERFS) Group. Risk factors for cerebral hemorrhage in the era of well-controlled hypertension. Stroke 1996; 27(11): 2020-5. [http://dx.doi.org/10.1161/01.STR.27.11.2020] [PMID: 8898809]

[29] Kim JK, Shin JJ, Park SK, Hwang YS, Kim TH, Shin HS. Prognostic factors and clinical outcomes of acute intracerebral hemorrhage in patients with chronic kidney disease. J Korean Neurosurg Soc 2013; 54(4): 296-301.

[http://dx.doi.org/10.3340/jkns.2013.54.4.296] [PMID: 24294452]

[30] Sakamoto Y, Koga M, Todo K, et al. SAMURAI study investigators. Relative systolic blood pressure reduction and clinical outcomes in hyperacute intracerebral hemorrhage: the SAMURAI-ICH observational study. J Hypertens 2015; 33(5): 1069-73.

[http://dx.doi.org/10.1097/HJH.0000000000000512] [PMID: 2566 8358]

[31] Gioia LC, Kate M, Dowlatshahi D, Hill MD, Butcher K. Blood pressure management in acute intracerebral hemorrhage: current evidence and ongoing controversies. Curr Opin Crit Care 2015; 21(2): 99-106.

[http://dx.doi.org/10.1097/MCC.0000000000000182] [PMID: 2568 9125]

[32] Shah SD, Kalita J, Misra UK, Mandal SK, Srivastava M. Prognostic predictors of thalamic hemorrhage. J Clin Neurosci 2005; 12(5): 559-61.

[http://dx.doi.org/10.1016/j.jocn.2004.08.010] [PMID: 15936200]

[33] Mayer SA. Recombinant activated factor VII for acute intracerebral hemorrhage. Stroke 2007; 38(2)(Suppl.): 763-7.

[http://dx.doi.org/10.1161/01.STR.0000254499.46122.22] [PMID: 1726 1734]

[34] Mendelow AD, Gregson BA, Rowan EN, Murray GD, Gholkar A, Mitchell PM. Early surgery versus initial conservative treatment in patients with spontaneous supratentorial lobar intracerebral haematomas (STICH II): a randomised trial. The Lancet Elsevier 2013; 382(9890): 397-408. 